\title{
Remote Sensing and Geographic Information System for Inferring Land Cover and Land Use Change in Wuhan (China), 1987-2006
}

\author{
Kanyamanda Kasereka (Corresponding author) \\ School of Environmental Studies, Institute of Ecology and Environmental Sciences \\ China University of Geosciences, Wuhan 430074, Hubei, China \\ Tel: 86-13006150220 E-mail: kanyhermen@gmail.com \\ $\mathrm{Gu}$ Yansheng \\ School of Environmental Studies, Institute of Ecology and Environmental Sciences \\ China University of Geosciences, Wuhan 430074, Hubei, China \\ E-mail: yansheng_gu@yahoo.com.cn \\ Innocent Ndoh Mbue \\ School of Environmental Studies, Institute of Ecology and Environmental Sciences \\ China University of Geosciences, Wuhan 430074, Hubei, China \\ E-mail: holyinnocent2001@yahoo.co.uk \\ Mamadou Samake \\ School of Environmental Studies, Institute of Ecology and Environmental Sciences \\ China University of Geosciences, Wuhan 430074, Hubei, China \\ E-mail: sitsam2003@yahoo.fr
}

\begin{abstract}
This study evaluates land use /land cover changes (LULCC) in Wuhan city, China, between 1987-2006 using satellite imagery data. Spatial and temporal dynamics of LULCC were quantified using three landsat TM images (1987, 1994 and 2006). The maximum likelihood supervised classification algorithm and post classification Change detection technique in GIS were also used. The analysis revealed that forest and urban growth over the study period changed by $15.57 \%$ and $8.66 \%$ respectively, resulting in a significant decrease in the area of cultivated land $(16.88 \%)$ and water $(7.35 \%)$. For the three main towns that make up Wuhan city, Wuchang increased in water, urban and cultivated land, and a decrease in forest cover; Hanyang increased in urban area and decreases in cultivated land, water and forest, while in Hankou, cultivated land and forest increased, urban and water covers decreased. The overall accuracy of the derived LULCC maps ranged from $88 \%$ to $92 \%$. The outcomes of this research will benefit society through the creation of reliable land cover information for better decision making. However, to identify how information diffusion and spatial externalities could affect the spatial pattern and composition of land cover over time, agent-based techniques could be more helpful.
\end{abstract}

Keywords: Wuhan, Land use and land cover, Remote sensing, GIS, Change detection, Agent-based techniques

\section{Introduction}

Land use/land cover arrangement makes landscape patterns and constitutes a key element in the study of global environmental change. Land use /land cover change(LULCC) is a dynamic, widespread and accelerating process, mainly driven by natural phenomena and anthropogenic activities, which in turn drive changes that would impact natural ecosystem (Ruiz et al. 2003; Turner and Ruscher, 2004). For instance, land use practices have played a role in changing the global carbon cycle and, possibly, the global climate: Since 1850, roughly 35\% of anthropogenic Carbon dioxide $\left(\mathrm{CO}_{2}\right)$ emissions resulted directly from land use (Foley et al. 2005) of which urbanized areas represent $97 \%$ of global anthropogenic $\mathrm{CO}_{2}$ emissions (svirejeva-hopkins et al., 2004). $\mathrm{CO}_{2}$ is the major green house gas responsible for the global warming (intergovernmental panel on climate change IPCC, 2007). Land cover changes also affect regional climates through changes in surface energy and water balance (Foley J.A. et al. 2005). These changes have become a central component for managing natural resources and monitoring environmental changes (Bottomley 1998; Muttitanon and Tripathi 2005). Studies of the detailed history of LULCC in an area can help to explain the spatial extent and degree of the change itself and help to assess the directions and degree of other human related environmental changes. Therefore, a lot of land cover and land use change models have been developed for assessing change on land use patterns for different purposes (U.S. EPA 2000).

The Chinese economic reform 1978 has been a spectacular economic development. Trade was opened to the outside world and the contract responsibilities system was implemented in agriculture. This has resulted in improved living standards, the GDP per capita and investments have increased, urban growth, etc. (Stephane Dee,1998; Sun Sheng, H. and Xiang WU, 2004). However, the dramatic change urbanization and industrialization has led to considerable loss of cultivated land. Based on the report from the ministry of land and 
resources (MLR), China's cultivated land area decreased by around 4 million hectares (ha) due to conversion of cropland into construction activities (roads, settlements, industry and mining), reforestation and natural disasters between 1988 and 1995, and by 7.6million ha between 1996 and 2003 (Cheng and Masser, 2003; Jixiang and Yonghong, 2007). Urbanization is an inevitable process due economic development and rapid population growth. Encroachment of urban settlements on agricultural lands may pose dire consequences such as land degradation and desertification (Aboel Ghar; Shalaby, A. and Tateishi, 2004 a, b). The ever increasing population causes increasing pressure on areas already inhabited and could cause a decrease in area per capita. Therefore, determining the trend and the rate of land cover conversion are necessary for the development planner in order to establish rational land use policy. For this purpose, the temporal dynamics of remote sensing data can play an important role in monitoring and analyzing land cover changes. Accurate and up-to-date land cover change information is necessary to understanding and assessing the environmental consequences of such changes (Giri, Zhu and Reed, 2005). While remote sensing has the capability of capturing such changes, extracting the change information from satellite data requires effective and automated change detection techniques (Roy, Lewis and Justice, 2002).

Digital change detection is the process of determining and/or describing changes in land cover and land use properties based on co-registered multi-temporal remote sensing data. The basic premise in using remote sensing data for change detection is that the process can identify change between two or more dates that is uncharacteristic of normal variation. Numerous researchers have addressed the problem of accurately monitoring land cover and land use change in a wide variety of environments using remotely sensed data (Yang and Lo, 2002; Jensen and Schill, 2007). Remotely sensed data have been used to characterize patterns of land cover change at scales from a few meters to a few degrees in latitude by longitude depending on the sensor (NRC, 2008). They offer a historical and recent perspective on landscape dynamics (Peterson et al. 2004). Using remotely sensed data, different types of land cover changes have been monitored for instance in coastal zone management (Huang and Fu 2002; Alphan 2004; Muttitanon and Tripathi 2005; Kesgin, 2007), in urban development (Mundia and Aniya 2005; Tardie and Congalton 2007), in cultivated land management (Zhao et al., 2004), in wetlands management (Munyati, 2000) and in forest fire monitoring (Ayanz et al. 2003). To date, several change detection methods have been developed to assess variations in LULCC using satellite data (Jensen, 2007).

To date, several change detection methods, the process of identifying differences in the state of a feature or phenomenon by observing it at different times (Jensen, 2007), such as image differencing, ratios or correlation, etc exist and theses might be attributable to change (Jensen, 2007; Lunetta,R.S. and Elvidge, C.D., 1998). Of these techniques, the pre- and post-classification comparisons have been extensively used (Singh, 1989; Coppin et al., 2004). However, the simple detection of change is rarely sufficient in itself: information is generally required about the initial and final land cover or types or land uses, the "from-to" analysis (Khorram et al., 1999). Furthermore, the detection of image differences may be confused with problems in phenology and cropping, and such problems may be exacerbated by limited image availability and poor quality in temperate zones, and difficulties in calibrating poor images. Post-classification comparisons of derived thematic maps go beyond simple change detection and attempt to quantify the different types of change. The degree of success depends upon the reliability of the maps made by image classification. Broadly speaking, large-scale changes such as widespread logging or major urban development might be mapped reasonably easily, whereas evolutionary changes such as erosion, succession, colonization or degradation, the boundaries may be indistinct and class-labels uncertain (Foody and Boyd, 1999).

The objectives of this study are; to provide a recent perspective for land cover types and land cover changes that have taken place in Wuhan (China), from 1987 to 2006 using remote sensing and GIS data, and to examine the capabilities of integrating remote sensing and GIS in studying the spatial distribution of different land cover changes. The approach for this study is based on the sequence of steps for land cover change detection. The main procedures include; image pre-processing, image classification and change detection.

\section{Materials and Methods}

\subsection{Study area}

Wuhan city is located in central China in Hubei province. Its East longitude $113^{0} 41^{\prime}-115^{0} 05^{\prime}$ and North latitude $29^{0} 58^{\prime}-31^{0} 22^{\prime}$, lies in the East of Jianghan Plain and the confluence of the middle reaches of the Yangtze River and Hanshui River(Figure 1). The metropolitan area comprises three parts, Wuchang, Hankou, and Hanyang commonly referred to as the three towns of Wuhan, hence the name Wuhan, which is combination of "Wu" from Wuchang and "Han" from Hankou and Hanyang. These three towns were consolidated and established in 1927. These three towns face each other across the rivers and linked by four bridges. Wuhan city has eight districts (Jiang an, Jianghan, Qiaokou, Hanyang, Wuchang, Qingshan, Hongshan, Caidian), two suburbs (Dongxihu, Hannan) and three counties (Wuchang, Huangpi, Xingzhou).

The total area is about $8494.41 \mathrm{~km}^{2}$, most of which is plain and decorated with hills and a great number of lakes and pools. Wuhan has a simple geographical structure, low and flat in the center and hilly in the south, with the 
Yangtze and Han Rivers winding through the city. The city's climate is subtropical, characterized by humid monsoon with abundant rainfall and four distinctive seasons. Wuhan is known for its oppressively humid summers, when dew point can often reach $26^{\circ} \mathrm{C}$ or more. Spring and autumn are generally mild, while winter is cool with occasional snow. In the past thirty years, the average annual rainfall is $1269 \mathrm{~mm}$, mainly from June to July; yearly temperature is $15.8^{\circ} \mathrm{C}-17.5^{\circ} \mathrm{C}$, yearly frost free period lasts 211 to 272 days and yearly sunlight duration is 1810 to 2100 hours.

According to the most recent census (August, 2007) Wuhan's population was estimated to be 9.7 million of which 6.7 million is urban. It is considered a great industrial, commercial and transportation hub of central China.

\subsection{Data acquisition and preparation}

Landsat images in Wuhan city (Figure 1) were acquired from United States Geological Survey (USGS). Three periods of landsat 4-5 Thematic Mapper (TM) images were selected to evaluate LULCC in Wuhan: 26 September 1987; 29 September 1994 and 01 November 2006. Wuhan City is entirely contained (covered) within four scenes, respectively path and row; 122-38, 123-38, 122-39 and 123-39. Only scene 123-39 was used for this study. The others scenes for analysis for the year under consideration were not available. Scene 123-39 covers most parts of Wuhan city where urban growth has occurred (Douty and Jiangfeng, 2008a). Each landsat image was enhanced and georeferenced to Wuhan local coordinate system UTM, Datum, WGS 84; Zone 49N. Topographic map (1:50 000 scale), based on already georeferenced 1994 image, was used as reference to perform image-to-image rectification for the image 1987 and 2006. All reflective bands were used in image classification. The thermal Infrared band (band 6) was excluded. To avoid altering the original pixel brightness values of the images, these data were resampled using nearest neighbor algorithm. The root mean square error (RMSE) for each of the images was 0.2 and 0.3 for the 1987 and 2006 respectively. Radiometric correction was used to remove or reduce the inconsistency between the values surveyed by sensors and the spectral reflectivity and spectral radiation brightness of the objects on the surface (Leonardo et al. 2006). This was followed by a two standard deviation stretch on each image in order to ignore the highest and lowest values so that more detail can be assigned to the areas in between. This improves the interpretability of the image. Erdas Imagine 9.2 was helpful in processes highlighted above.

The data used as reference included land use maps and Google Earth. These were used for both training area selection and assessment of the classification and map accuracy. In addition field work was conducted in the study area in October 2009 to familiarize the researcher with the study area and to collect ground control points (GCPs) using a hand held global positioning system (GPS). A total of 100 GCPs were collected but not all GCPs could be used for accuracy because the GCPs collection was done in October 2009 when the most recent image we have is for 2006 .

\subsubsection{Image classification}

The overall objective of the image classification procedure is to automatically categorize all pixels in an image into land cover classes or themes (Lillesand \& Kiefer, 1999). The maximum likelihood classifier quantitatively evaluates both the variance and covariance of the category spectral response patterns when classifying an unknown pixel so that it is considered to be one of the most accurate classifier since it is based on statistical parameters. Supervised classification was done using ground checkpoints and digital topographic maps of the study area. A modification of the Anderson scheme of LULC classification was used (Jensen, 2007). The area was classified into four main classes: water (all area of open water, including rivers, stream, lakes, ponds and reservoirs); forest (including forest parks, shrubs, horticulture); cultivated land (agricultural area, grassland, crop fields, bush lands, fallow lands); urban (depict residential of single or multiple family houses, commercial and industrial buildings as well as open transportation facilities, airports, highways, railways).

\subsubsection{Accuracy assessment}

Generally, classification accuracy refers to the extent of correspondence between the remotely sensed data and reference information (Congalton, 1991). In order to assess the accuracy of land cover maps extracted from landsat data, a total of 100 random pixels were generated for all data. The location of the 100 points was chosen using random method to represent different land cover classes of the area. In order to increase the accuracy of land cover mapping of the three images, ancillary data and the result of visual interpretation was integrated with the classification result using GIS in order to improve the classification accuracy of the classified image. A non parametric kappa test was also adopted to measure the classification accuracy as it accounts for all elements in the confusion matrix rather than just the diagonal elements (Rosenfield \& Fitzpatirck-lins, 1986). The total accuracy of the landsat derived LULCC data was $92 \%, 88 \%$ and $90 \%$ with corresponding kappa statistics of $0.84 \%, 0.81 \%$ and $0.85 \%$ respectively for 1987,1994 , and 2006 ; corroborating the standard accuracy of $85 \%$ 90\% for LULCC mapping studies as recommended by Anderson et al., (1976).

\subsubsection{Change detection}

The post-classification change detection technique was employed, which is efficient in detecting the nature, rate and location of changes, and has been successfully used in a number of researches done in urban environments 
(Hardin et al., 2007). Firstly, the images were imported in Arc Map 9.3 and converted into vector format. An overlay procedure using the intersect function of Arc Map 9.3 was adopted with each of the classified TM image and towns (Wuchang, Hankou, Hanyang) boundary layer. Using the calculate area function of arc Map, land area for each land use type in each town was calculated on the intersect output. In this way the area of each town was exported into excel for further analyses. The area obtained was divided by 10000 to convert area from meter to hectare, because TM images were referenced to the UTM system which is in meters. Application of this technique resulted in two way-cross- matrix, describing the main types of change in the study area. Cross tabulation analysis on a pixel by pixel basis facilitated the determination of the quantity of conversions from a particular land cover class to other land use categories and their corresponding area over the period evaluated.

The comparison of the land use land cover statistics assisted in identifying the percentage change, trend and rate of change between 1987 and 2006. In achieving this goal, the first task was to develop the figures showing the area in hectares determining the percentage change for each year (1987, 1994 and 2006) measured against each land use land cover type. To determine the trend of change, observed change was divided by sum of changes multiplied by 100 :

(Trend) percentage change $=$ observed change $* 100$

\section{Sum of change}

The trend area changed measured against two land use land cover type was calculated as follow: the difference between the observed change in area (i.e. urban) in later period q (e.g. 2006 year) and observed change in area (i.e. urban) in early period p (e.g. 1987 year)

Trend area changed $=$ observed change $q$ - observed change $p$

In obtaining annual rate of change, the area changed is divided by the number of study year 1987-1994(7 years), 1994-2006(12 years).

\section{Results and Discussion}

\section{1 land use and land cover change in Wuhan city (1987-2006)}

Land cover changes over the 19 years period for the different categories are depicted in Figure 2.

The GIS analysis revealed that the area occupied by water and cultivated land (C.L.) decreased by $-6.57 \%$ and $-23.49 \%$ respectively in period between $1987-1994$; whilst forest areas increased by $26.07 \%$ in the same period 1987-1994. This result has corroborated the findings made in "report environmental profile of the Wuhan municipal area in 1996". The change was also noticed by the decline in water area $0.75 \%$ and forest area $-10.5 \%$ over the period (1994-2006). On the other hand, cultivated land increased by $6.61 \%$. The net change in water, forest and cultivated land areas over the study period were $-7.35 \%, 15.57 \%$ and $-16.88 \%$ respectively (Figure 3 ).

Overall changes in the landscape show an increased trend for urban development against water and cultivated land areas. Urbanization is generally related to demographic change and economic growth (Li, Sato and $\mathrm{Zhu}$, 2003; Liu, J., Zhan, J. and Deng, X., 2005). This is partly a result of the economic reform of china in 1978. Especially after land reform in 1987, rapid urban growth has taken place in china and urban population has remarkably expanded (www.starmass.com; Cheng, J. and Masser, I. 2003). As one of the most developed cities in china, Wuhan has experienced rapid urban expansion and its population increased to 6.29 million in 1987 , 7.050 million in 1994 and was estimated to be 9.7million in 2006. Meanwhile, water, cultivated land and forest decrease in order to support population growth such as the population habitation.

The increase in urban areas can partly be explained by the increase in per capita investment on housing. In 1985, the per capita living space increased to $5.2 \mathrm{~m}^{2}$ and in $1988,5.8 \mathrm{~m}^{2}$. In the 20 years, between 1978 and 1998 , there were 43.7 billion RMB Yuan (note1) invested in housing development. A total residential floor area of 58.3 million $\mathrm{m}^{2}$ was built. By 1998, Wuhan's per capita living space was $8.1 \mathrm{~m}^{2}$. From 1998 to 2002, Wuhan showed rapid housing development. The developed land area in 2002 was almost four times as big as that of 1998. Housing investment increased from 4.81 billion RMB Yuan in 1998 to 9.94 billion RMB Yuan in 2002 (Sun Sheng, H. and Xiang WU, 2004). The main driving force for urban expansion in Wuhan city, like it is the case in other Chinese cities, is the phenomenon of development zones that are created to host foreign direct investment. The major development zones in Wuhan city include Wuhan Economic and technological development zone, Guandong and Guannan industrial parks and Nanhu and Changhong industrial parks. There are many others in each district of Wuhan city (www.starmass.com; Douty, C. and Jiangfeng Li, 2008b). Most development zones are discontinuous from the built- up area and are located on the urban fringe, where farmland has to be expropriated from peasants and local government needs to invest in basic infrastructure, including roads, water, drainage system and power. Comprising industrial, commercial and residential land use and occupying large amount of farmland (sometimes over $80 \%$ ) (Deng and Huang, 2004).

The 1990s was a decade during which Wuhan experienced rapid expansion and restructuring in land use. An empirical test of land use changes using Shannon Entropy revealed that transportation and industrial land use grew especially fast during the first half of the 1990s, with new areas added mainly in the industrial district in Hanyang and the peripheries of all the three towns. Transportation and industrial land use kept on growing in the 
second half of the 1990s, but at a slower pace. Interestingly, the green area shrunk during the late 1990s (Sun Sheng, H. and Xiang WU, 2004).

In a similar study, Ningrui Du, Henk Ottens and Richard Sliuzas (2009) also reported similar changes in land cover from 1993 to 2004 where 585 ha of lake and 345 ha of shallow water bodies have been transformed into other types of land use. The cultivated land and forest areas trend can be attributed to the agricultural land protection ordinance which was introduced by the Chinese government in 1994 and the Land Management Ordinance of 1998. Provincial governments are required to take the responsibility to maintain a dynamic balance of cultivated land in their jurisdictions. Losses of cultivated land have to be compensated by reclaiming new land and other means (mainly rehabilitating damaged land and reusing deserted land) (Hong Yang and Xiubin Li, 2000).

\section{2 land use and land cover change in per Wuhan's towns (1987-2006)}

Significant net changes in the different land cover categories were recorded in all three Wuhan towns (Figure4)

The nature of land cover change revealed that in Wuchang town urban area increased by $1.91 \%$ which is equivalent to annual average of $0.1 \%$ per year over the study period 1987-2006.

Water area has increased by $48.93 \%, 54 \%$ and $60.65 \%$ in 1987,1994 and 2006 respectively. This represented net increase of 5.9\%, 5.82\% and 11.72\% between 1987-1994, 1994-2006 and 1987-2006 respectively.

Forest area has been decreased: $51.99 \%, 30.9 \%$ and $32.58 \%$ in 1987,1994 and 2006 respectively with a net loss and gain:-21.09\%, 1.68\%, -19.41\% between 1987-1994, 1994-2006 and 1987-2006 respectively. The cultivated land area has shown the trend of net rising over the study time by $1.73 \%$ in $1987-2006$. The cultivated land area trend can be attributed due to obvious reasons already alluded to elsewhere in this study.

In Hanyang town, the urban and forest areas increased by $1.5 \%$ and $17.68 \%$, representing an average annual change of $0.078 \%$ and $0.93 \%$ per year respectively during $1987-2006$.

Cultivated land area decreased by $1.3 \%, 4.55 \%$ and 5.85\% per year between 1987-1994, 1994-2006, $1994-2006$ respectively.

Water surface has decreased by 3.33\%, 2.42\%, and 5.75\% for the periods 1987-1994, 1994-2006 and $1987-2006$ respectively. This result is in line with the findings of Liu et al., 2004, who concluded that the number of lakes decreased in Wuhan city in 1988 by 35, and declined to 27 in 1998 due to the draining and reclaiming the lakes to urban areas.

Finally, in Hankou, urban and water areas decreased by $-3.41 \%$ and $-5.75 \%$, representing an average annual decrease of $0.17 \%$ and $0.3 \%$ per year respectively from $1987-2006$.

Forest and cultivated land areas increased by $1.73 \%$ and $4.13 \%$, representing an annual average change of $0.09 \%$ and $0.21 \%$ per year respectively from $1987-2006$.

The noticeable dynamics in the sense of increasing area of two land use type forest and cultivated land can be attributed to the large area occupied by two largest Wuhan's counties (Huangpi and Xinzhou) with the largest gross agricultural output value (GAOV= including farming, forestry, animal husbandry, and fishery) (Sun Sheng, H. and Xiang WU, 2004). This can also be attributed to the agricultural land protection ordinance which was introduced by the Chinese government in 1994 and Land Management Ordinance of 1998. Provincial governments are required to take the responsibility to maintain a dynamic balance of cultivated land in their jurisdictions. Losses of cultivated land have to be compensated by reclaiming new land and other means (mainly rehabilitating damaged land and reusing deserted land) (Hong Yang and Xiubin Li, 2000).

Urban expansion was achieved at the expense of reducing and fragmenting cultivated land, water body, and forest. The invasion of urban area into forested land may have reduced the capacity of forest's air filtering. The nitrogen oxides (N0x ) emissions in Wuhan city increased during the past 12 years: N0x concentration was $0.054 \mathrm{mg} / \mathrm{m}^{3}$ in 1987 (Yang et al., 1991), and increased to $0.068 \mathrm{mg} / \mathrm{m}^{3}$ in 1993 , then to $0,1 \mathrm{mg} / \mathrm{m}^{3} \mathrm{in}$ 1999( Hu et al.,2002). A study on LULCC and impacts in Atlanta Metropolitan Area in Georgia indicated that forest coverage correlates strongly and negatively with N0x emissions (Lo and Quattrochi, 2003).

\section{Conclusion}

The objectives of this study were to provide a perspective for land cover types and land cover changes that took place in Wuhan city from 1987 to 2006, to integrate visual interpretation with supervised classification using GIS and to examine the capabilities of integrating remote sensing and GIS in studying the spatial distribution of different land cover changes. It was found that integrating visual interpretation with supervised classification led to significant improvement in overall accuracy. The study area has undergone significant land cover change as a result of development projects either agricultural or urbanization. Considerable changes took place in land cover categories, especially urban sprawl. The areas of natural vegetation and water have decreased. Integrating GIS and remote sensing provided valuable information on the nature of land cover changes especially the area and spatial distribution of different land cover changes. Such changes are coming at the expense of environmental security. These are catalyzed by changes in government policies. This problem needs to be seriously studied, 
through multi-dimensional fields including socioeconomic, in order to mitigate the impact of climate change, while sustaining human livelihoods, biodiversity and the ecological services it provides. However, to identify how information diffusion and spatial externalities could affect the spatial pattern and composition of land cover over time, agent-based techniques could be more helpful.

\section{References}

Aboel Ghar, M.; Shalaby, A. and R. Tateishi. (2004). Agricultural land monitoring in the Egyptian Nile Delta using Landsat data. The International Journal of environmental studies 61 (2004) (6), pp. 651-657.

Alphan, H. (2003). Land use change and urbanization in Adana, Turkey. Land Degradation and Development, 14 (6), 575-586. Doi.wiley.com/10.1002/ldr.581.

Anderson et al., (1976). Land use and Land cover Classification System for Use with Remote sensor Data.

Ayanz, J. S.-M., Barbosa, P., Schmuck, G., Liberta, G., \& Schule, E. (2003). Towards a coherent forest fire information system in Europe: The European Forest Fire Information System (EFFIS). Options Mediterraneennes. Série B, 46, 5-16.

Bottomley, B. R. (1998). Mapping rural land use and land cover change in Carroll County, Arkansas utilizing multi-temporal Landsat Thematic Mapper satellite imagery. Dissertation, University of Arkansas. http://www.cast.uark.edu/local/brandon_thesis/.

Cheng, J. and Masser, I. (2003). Urban growth pattern modelling: a case study of Wuhan city, PR China. Landscape and Urban Planning, 62: 199-217.

Congalton, R.G. (1991). A review of assessing the accuracy of classifications of remotely sensed data. Remote sensing of environment 37, 35-46.

Coppin et al., (2004). Digital change detection methods in ecosystem monitoring: a review. International journal of remote sensing, 25(9), 1565-1596.

Deng, F.F and Y. Huang, (2004). Uneven land reform and urban sprawl in China: The case of Beijing. Progress in Planning, 61:211-236. DOI: 10.1016/j.progress.2003.10.004.

Douty, C. and Jianfeng, L. (2008a) Study of Urban expansion in the urban administrative Districts of Wuhan city, 1987-2005: A Remote Sensing and GIS perspective. Environmental Research Journal 2(6):290-298, 2008.

Douty, C. and Jiangfeng, Li. (2008b). Foreign Direct Investment (FDI) and Urban Restructuring in Wuhan: Implications for Developing China's Western Interior. International Business Management (5): 210-210.

Foley J.A. et al. (2005). Global consequences of land use vol. 309 www.sciencemag.org

Foody, G.M. and Boyd, D.S. (1999). Detection of partial land cover change associated with the migration of inner-class transitional zones, International Journal of Remote Sensing 20, pp. 2723-2740.

Giri, C., Zhu, Z. and Reed, B. (2005). A comparative analysis of the Global Land Cover 2000 and MODIS land cover data sets, Remote Sensing of Environment 94, pp. 123-132.

Hardin, P.J.,Jackson,M.W. and Otterstrom,S.M. (2007). Maping, measuring, and modeling urban growth. InR.R.Jensen, J.D.Gatrell,\&D.Mclean(Eds.), Geo-SpatialTechnologies In Urban Environments: Policy, Practice And Pixels(2 ${ }^{\mathrm{ND}}$ ED.).(Pp.141-176) Heidelberg:springer-velag.

Hong Yang and Xiubin Li. (2000). Cultivated land and food supply in China. Land Use Policy 17 (2000)73 -88.

Huang, W., \& Fu, B. (2002). Remote sensing for coastal area management in China. Coastal Management, 30, 271-276. Doi: 10.1080/08920750290042200.

$\mathrm{Hu}, \mathrm{H} ., \mathrm{Xie}, \mathrm{J}$. and Hou, Q. Z. (2002). 'The study on the variation of TSP, $\mathrm{SO}_{2}$, NOx and CO in Wuhan urban atmosphere', Environ. Prot. Sci. 28, 1-3.

IPCC. (2007). Summary for Policymakers. In: climate change 2007: the Physical Science Basis. Contribution of Working Group 1 to the 4th Assessment Report of the Intergovernmental Panel on climate change, in: Solomon, S., D. Qin, M.Manning, Z. Chen, M.Marquis, K.B. Averyt, M.Tignor and H.L.Miller (Eds). Cambridge University Press, Cambridge United Kingdom and New York, NY, USA. http:/www.ipcc.ch/pdf/assessment-report/ar4/wg1/ar4-wgl-spm.pdf.

Jensen, J.R. (2007). Introductory digital image processing: a remote sensing perspective. 3rd Edn. Science Press and Pearson Education Asia Ltd: Beijing. ISBN: 0-13145361-0.

Jensen, J. R., \& Schill, S. R. (2007). General steps required to perform change detection. Vol. 3: Introductory Digital Image Processing, University of South Carolina. http://www.cas.sc.edu/geog/rslab/Rscc/mod8/8-1/8-1.html.

Jixiang, Z. and Yonghong, Z. (2007). Remote sensing research issues of the National Land use Change Program of China, International society for photogrammetric and Remote Sensing, Inc.(ISPRS),62(2007)461-472. Doi:10.1016/j.isprsjprs.2007.07.002. 
Kesgin, B. (2007). Research on monitoring coastal land use change based on remote sensing techniques. Dissertation, Ege University.

Khorram, S. Biging, G.S. Chrisman, N.R., Congalton, R.G Dobson, J.E. and Ferguson, R.L. et al. (1999). Accuracy assessment of remote sensing-derived change detection, American Society of Photogrammetry and Remote Sensing, Bethesda.

Leonardo, P., Franceisco, G., Jose, A., Sobrino, Juan, C., Jimenez, M. and Haydee, K. (2006). Radiometric correction effects in landsat multi-date /multisensory change detection studies, International Journal of Remote Sensing, 2, pp. 685-704.

Li, Sato, \& Zhu, (2003). Simulating spatial urban expansion based physical process. Landscape and urban planning. 64, 67-76.

Lillesand, T.M. \& Kiefer, R.W. (1999). Remote Sensing and Image Interpretation $4^{\text {th }}$ Ed. New York: Jonh Wiley and Sons 710 pp. ISBN: 0-471-25515-7.

Liu, J., Zhan, J. and Deng, X. (2005). Spatio-temporal patterns and driving forces of urban land expansion in china during the economic reform era. Ambio 34 (6), 450-455.).

Liu, Y. B.,Wang, Q. F. and Chen, H. M. (2004). 'The developing, protecting and planning envision of lakes in Wuhan City', Econ. Geogr. 24, 192-196.

Lo, C. P. and Quattrochi, D. A. (2003). 'Land-use and land-cover change, urban heat island phenomenon, and health implications: A remote sensing approach’, Photogram. Eng. Remote Sens.69, 1053-1063.

Lunetta,R.S. and Elvidge, C.D. (1998). Remote sensing change detection, Ann Arbor Press, MI"

Mundia, C. N. and Aniya, M. (2005). Analysis of land use/cover changes and urban expansion of Nairobi city using remote sensing and GIS. International Journal of Remote Sensing, 26(13), 2831-2849. Doi: 10.1080/01431160500117865.

Munyati, C. (2000). Wetland change detection on the Kafue Flats, Zambia by classification of a multitemporal remote sensing image dataset. International Journal of Remote Sensing, 21(9), 1787-1806. Doi: 10.1080/014311600209742.

Muttitanon, W., \& Tripathi, N. K. (2005). Land use/land cover changes in the coastal zone of Ban Don Bay, Thailand using Landsat 5 TM data. International Journal of Remote Sensing, 26(11), 2311-2323. Doi: 10.1080/0143116051233132666.

National Research Council (NRC) (2008). Earth observations from space: The first 50 years of scientific achievements. http://www.nap.edu/catalog/11991.html. Washington, D.C.: The National Academy Press.

Ningrui Du, Henk Ottens and Richard Sliuzas. (2009). Spatial impact of urban expansion on surface Water bodies A case study of Wuhan, China94(2010)175-185. DOI:10.1016/j.landurbanplan.2009.10.002

Peterson et al. (2004). Identifying historical and recent land cover changes in Kansas using postclassification change detection techniques. Transactions of the Kansas Academy of science, 107(3/4), 105-108. Doi: 10.1660/0022-8443(2004)107[0105: IHARLC] 2.0.CO; 2.

Rosenfield,G.H., \& Fitzpatirck-lins, K. (1986). A coefficient of agreement as a measure of thematic classification accuracy. Photogrammetric engineering and remote sensing, 52(2)223-227.

Roy, D.P., Lewis, P.E. \& Justice, C.O. (2002). Burned area mapping using multi-temporal moderate spatial resolution data - a bi-directional reflectance model-based expectation approach, Remote Sensing of Environment 83, pp. 263-286

Ruiz-Luna, A. and C.A. Berlanga-Robles. (2003). land use, land cover changes and costal lagoon surface reduction associated with urban growth in Norwest Mexico. Landscape Ecology, 18:159-171.

Shalaby, A.; Aboel Ghar, M. and R. Tateishi. (2004b). Desertification impact assessment in Egypt using low resolution satellite data and GIS, The International Journal of Environmental Studies 61 (2004) (4), pp. 375-384.

Singh, A. (1989). Digital change detection techniques using remotely-sensed data. International Journal of Remote Sensing, 10(6), 989-1003. Doi: 10.1080/ 01431168908903939.

Stephane Dee. (1998). Foreign investments in China: Determinants and Effects. Economics of Planning 31: 175-1994

Sun Sheng,H. and Xiang WU. (2004). City profile Wuhan.Vol.21(4), p.349-362. Doi:10.1016/j.cities.2004.03.007

Svirejeva-Hopkins,A., H.J.Schellnhuber and V.L.Pomaz. (2004). Urbanized territories as a specific component of the global carbon cycle. Ecological Modelling, 173:295-312. DOI:10.1016/j.ecolmodel.2003.09.022 
Tardie, P. S., \& Congalton, R. G. (2007). A change detection analysis: Using remotely sensed data to assess the progression of development in Essex County, Massachusetts from 1990 to 2001. Retrieved from University of New Hampshire Durham. URL: http:// www.unh.edu/natural-resources/pdf/tardie-paper1.pdf.

Turner, M.G. and C.L. Ruscher. (2004). Change in landscape patterns in Georgia, USA. Landscape Ecology , $1(4): 421-251$.

U.S. EPA. (2000). Projecting land-use change, a summary of models for assessing the effects of community growth and change on land-use patterns. EPA/600/R-00/098, from U.S. Environmental Protection Agency, Office of Research and Development, USA.

Yang, X., \& Lo, C. P. (2002). Using a time series of satellite imagery to detect land use and land cover changes in Atlanta, Georgia metropolitan area. International Journal of Remote Sensing, 23(9), 1775-1798.doi:10.1080/01431160110075802.

Yang, J. W., Zhang, N. D. and Zhang, Z. J. (1991). 'Pollution characteristics of NOx and its trend in Wuhan', Urban Ecol. Environ. 4, 34-38.

Zhao, G. X., Lin, G., and Warner, T. (2004). Using Thematic Mapper data for change detection and sustainable use of cultivated land: A case study in the Yellow River delta, China. International Journal of Remote Sensing, 25(13), 2509-2522. Doi: 10.1080/ 01431160310001619571.

Report Environmental profile of the Wuhan municipal area in 1996 www.starmass.com

\section{Note}

Note1: 1US\$ equals to 6, 8285 RMB Yuan (Chinese currency) at current market price

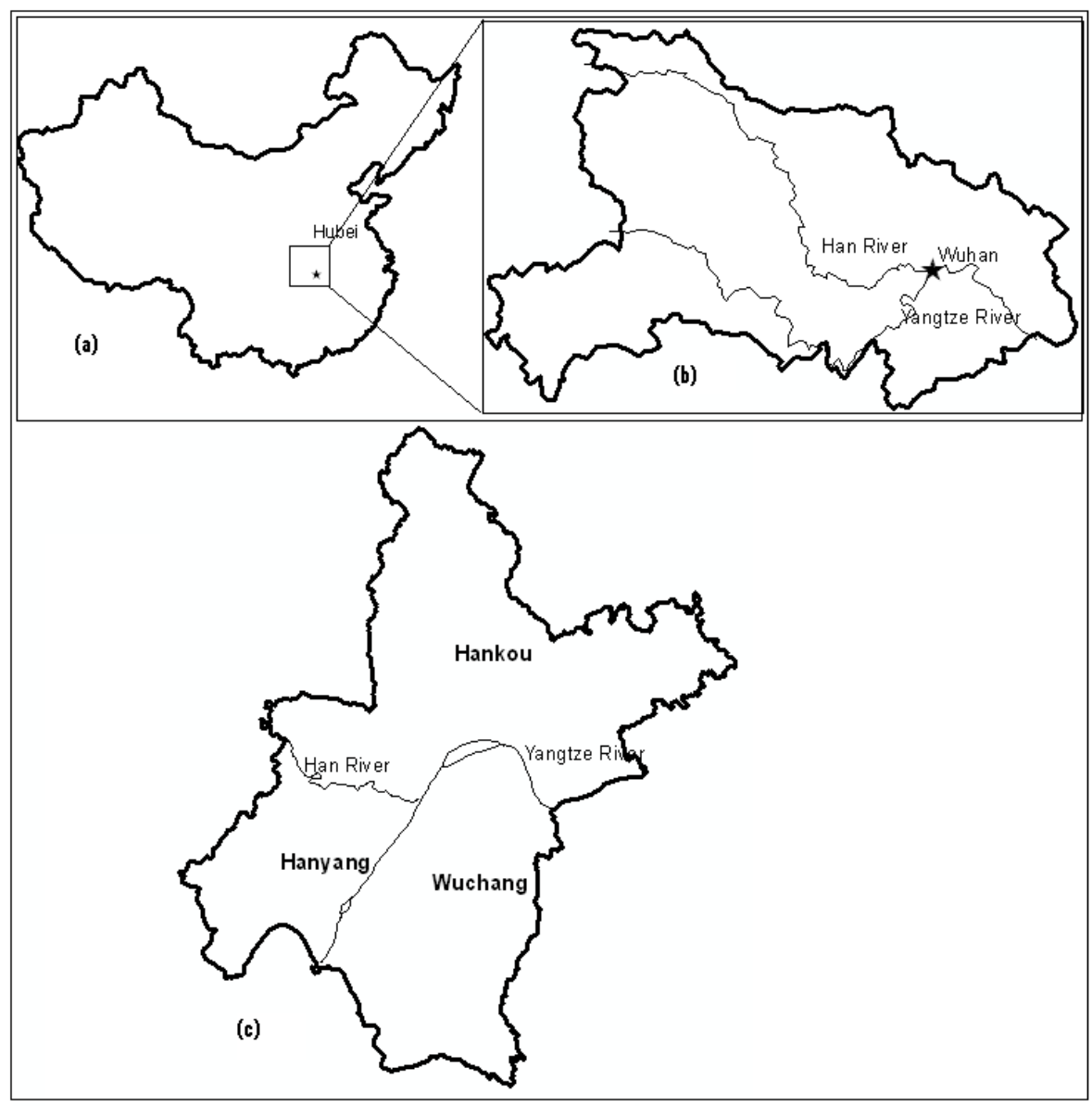

Figure 1. Location of Study area :( a) location of Hubei province in China;

(b) location of Wuhan in Hubei province and (c) location of three towns in Wuhan 


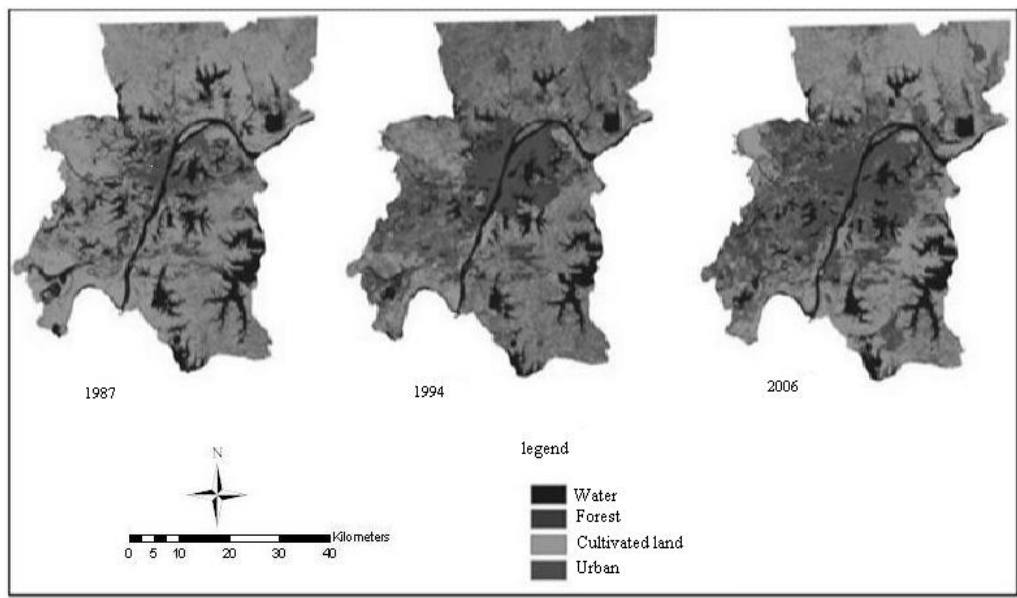

Figure 2. Land use land cover classifications map 1987, 1994, and 2006 for Wuhan city

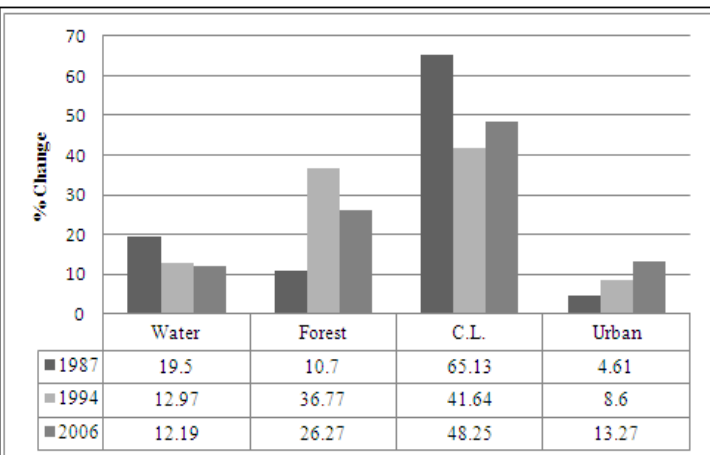

(a)



(b)

Figure 3. Percentage changes in land cover categories in Wuhan city during: (a) 1987, 1994 and 2006; (b) 1987-1994, 1994-2006 and 1987-2006

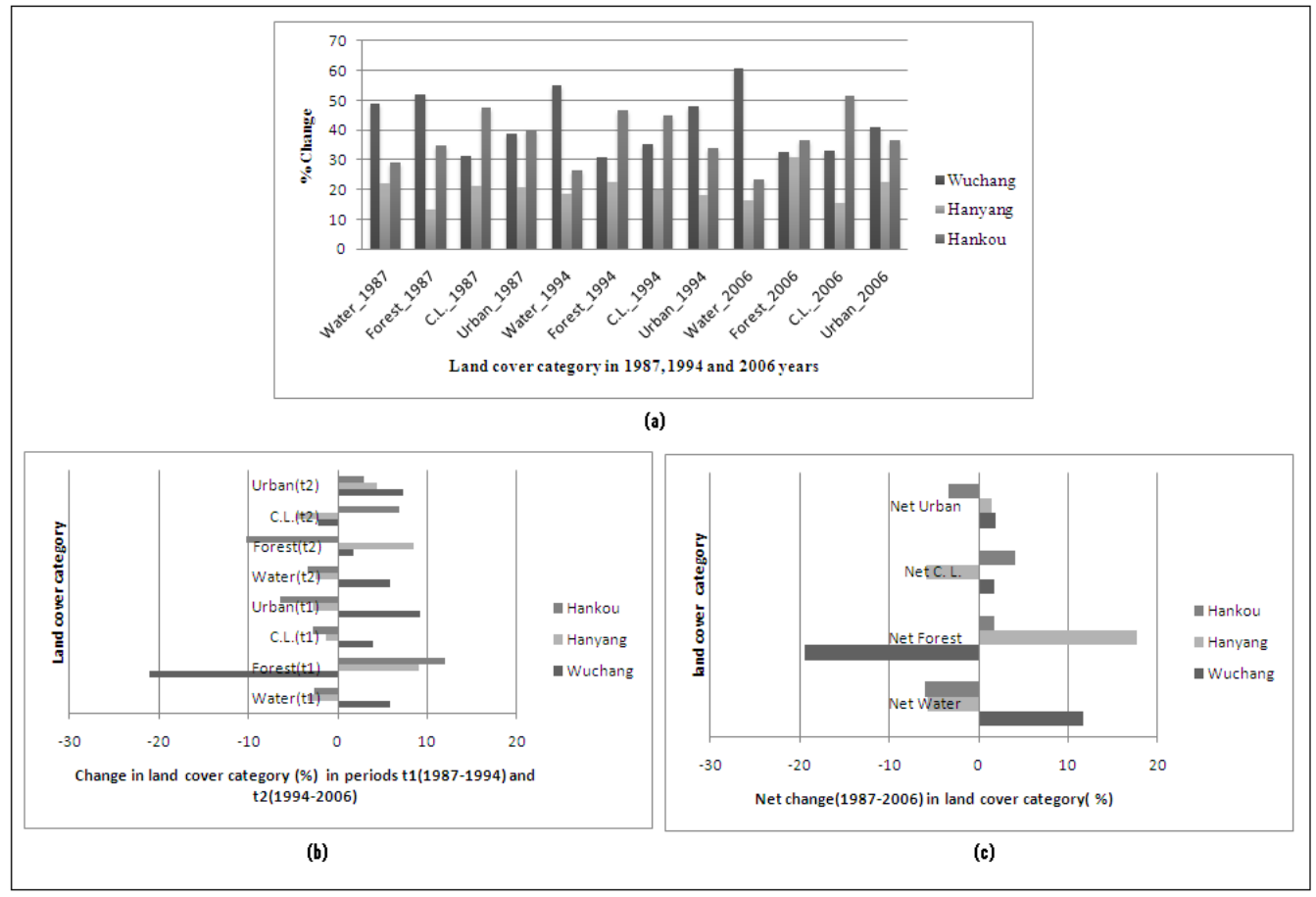

Figure 4. land cover categories in Wuhan's towns 